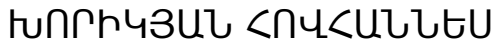

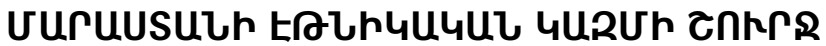

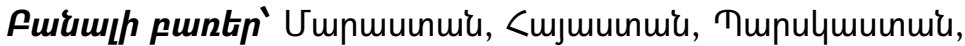

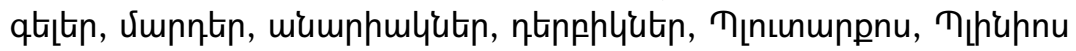
Uymq, Putunchnu, Uinnupnu:

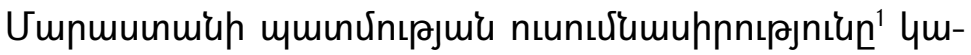

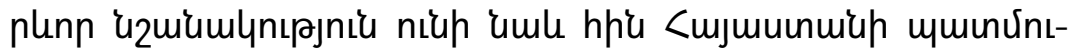

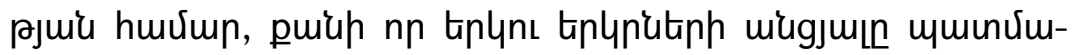

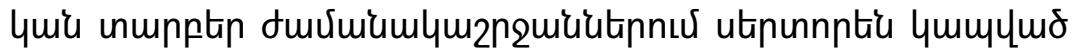

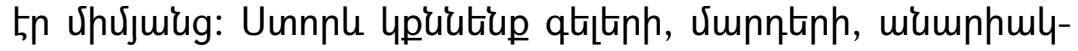

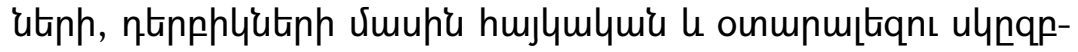

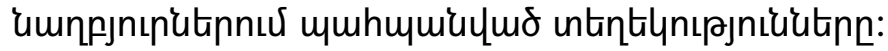

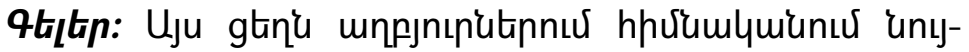

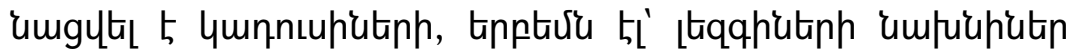

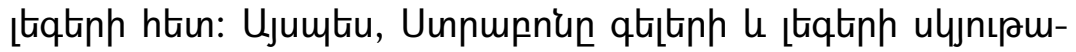

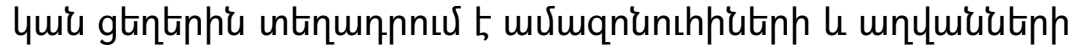

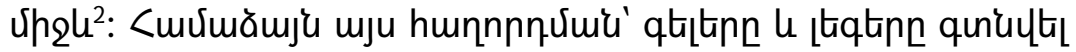

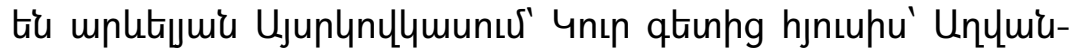

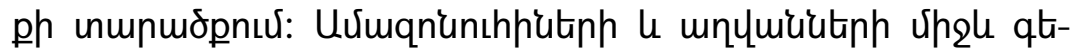

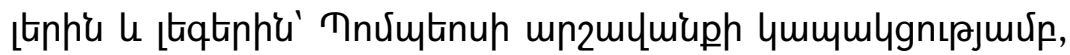

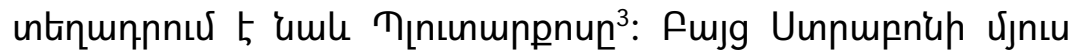

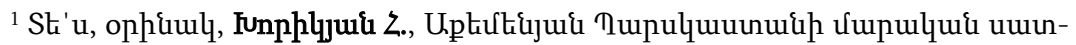

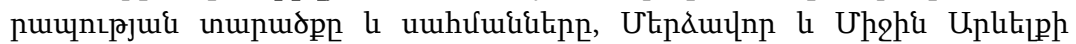

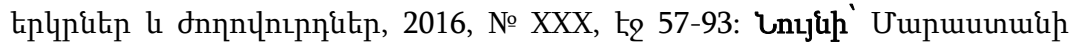

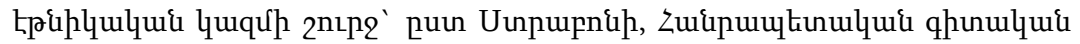
\{unuzpquil \{jnıptep, qjnuर्uph, 2012, tq 337-341:

2 Страбон. География в 17 книгах. Перевод, статья и комментарии Г. Стратановского. Ленинград, 1964, стр. 477.

${ }^{3}$ Плутарх. "Избранные жизнеописания". Т. II, Москва, 1987. Помпей. XXXV, стр. 312.
} 


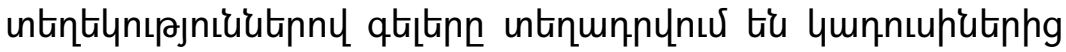

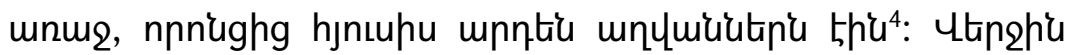

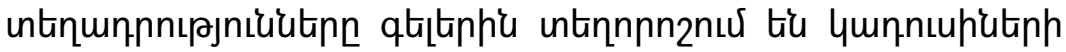
huplumiunıpjuर्up:

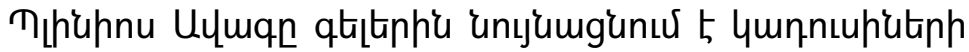

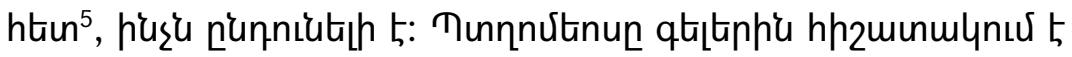

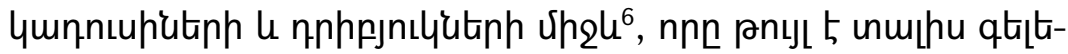

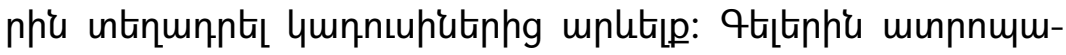

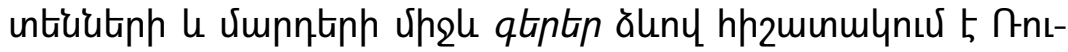
unu Фtuunnun:

${ }^{4}$ Страбон, стр. 481, 483.

${ }^{5}$ Pliny, Natural History, Vol. II, with an English translation by H. Rackham, Cambridge-Massachusetts-London, 1947, Loeb Classical Library, VI, 48, p. 372:

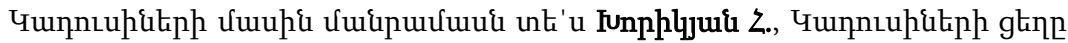

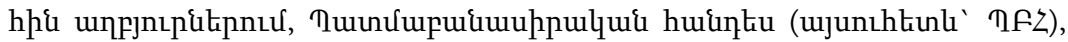
2011, № 3, ㄴ. 213-228:

${ }^{6}$ Humbach H., Ziegler S., Ptolemy Geography, book 6, Text and English/German Translations, Wiesbaden, 1998, pp. 42-43: Tunnnưtnuh «U.2huuphuqpnıpju\{»

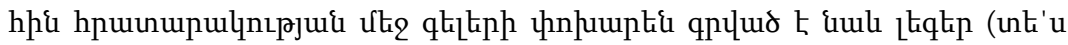
Claudii Ptolemaei Geographia, edidit C.F.A. Noebbe, t. II, Lipsiae, 1845, VI, 2, 5,

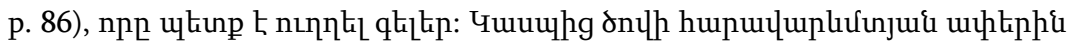

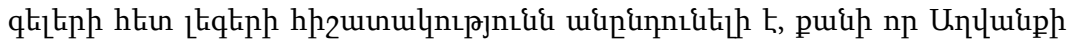

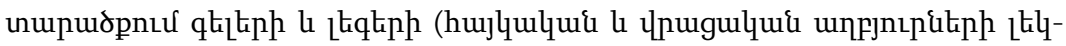

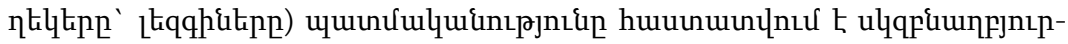

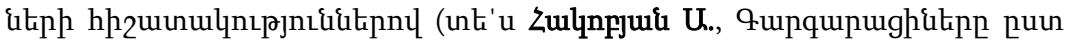

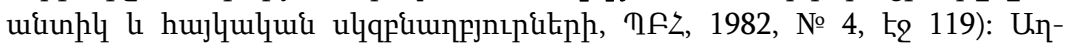

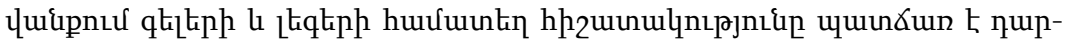

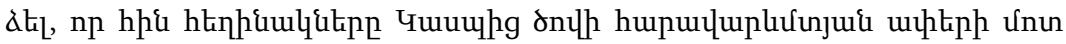

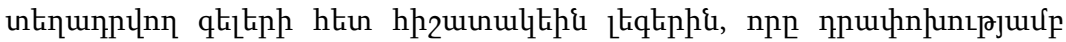

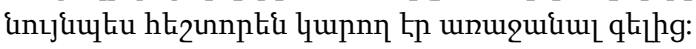

7 Латышев В., Известия древних писателей греческих и латинских о Скифии и Кавказе (ujunthtinl ' ИДПСК), Вестник древней истории (ujunthtinl' ВДИ), 1949, № 4, стр. 242. 


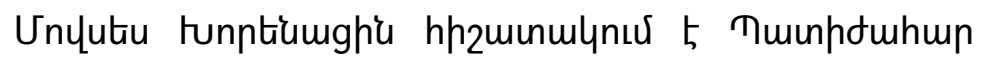

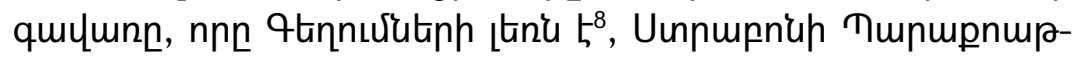

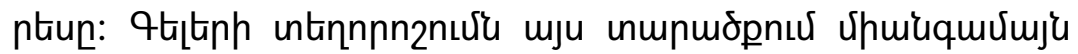

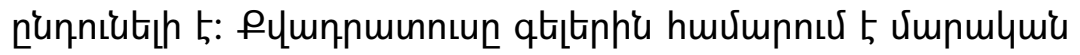

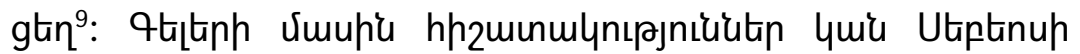

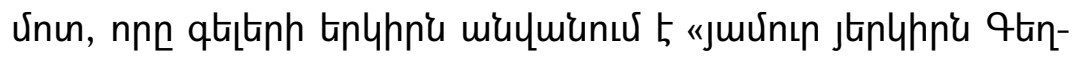

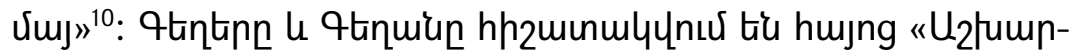

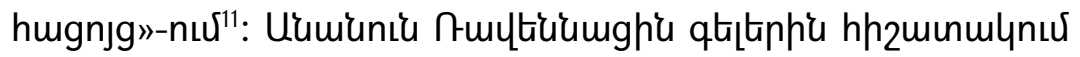

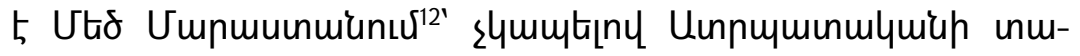
nuigph htin:

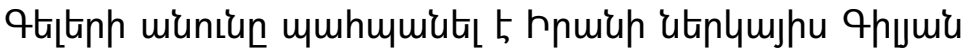

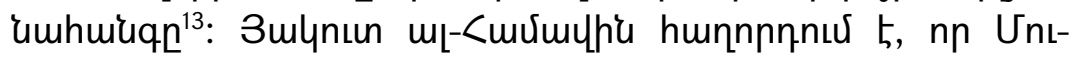

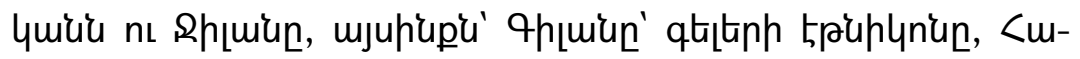

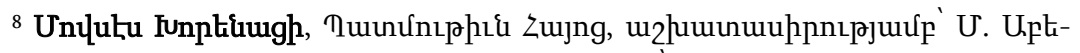

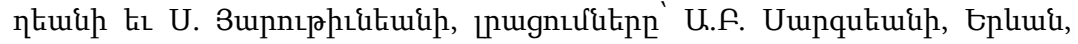
1990, to 182:

${ }^{9}$ Müller C., Fragmenta Historicorum Graecorum, Vol. III, Parisiis, 1849, p. 659, fr. 1.

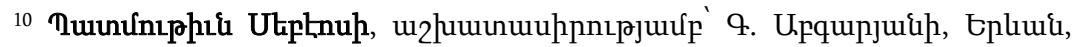

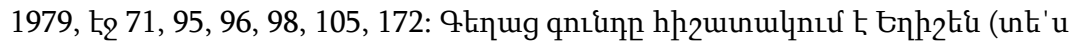

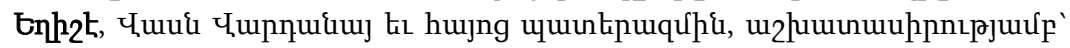
t. Stip-Uhquujuid, Epluwi, 1989, to 232):

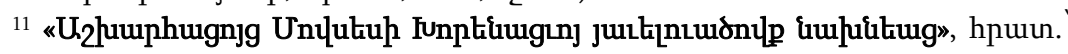
U. Unıpptuqu, Ч.titunhl, 1881, te 12, 40-41; Патканов К.П., Армянская Гео-

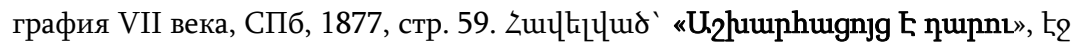

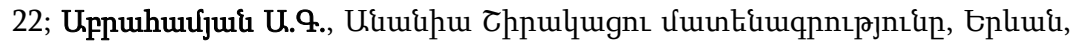

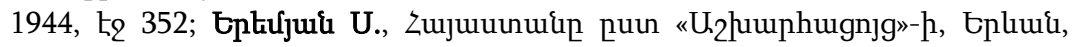

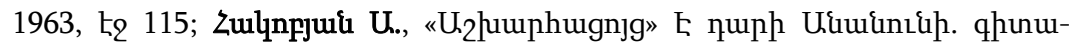

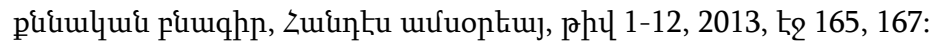

${ }_{12}$ Ravennatis Anonymi Cosmographia, ed. M. Pinder et Parthey, Berolini, 1860, II, 9, p. 62.

${ }^{13}$ St'u, ophiuul, Herzfeld E., The Persian Empire. Studies in Geography and Ethnography of the Ancient Near East, Wiesbaden, 1968, p. 196. 


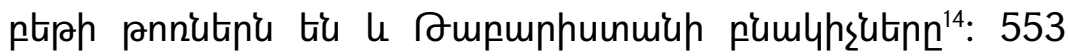

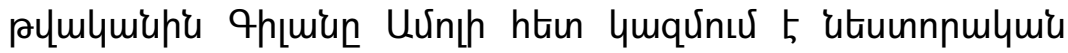
tumhulnuynunıpjnic ${ }^{15}$ :

Ujumhuny, ymnnsuhutinhe mqqulyhg qtitinn hurluium-

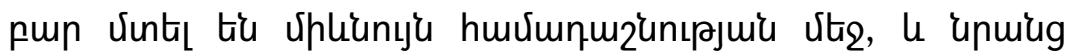

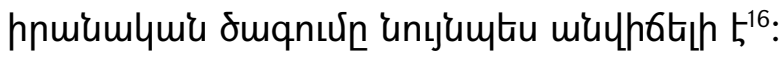

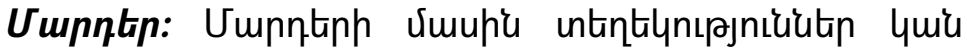

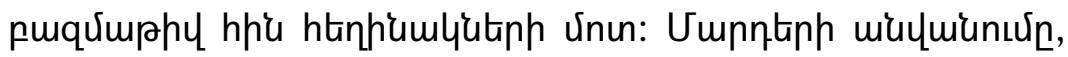

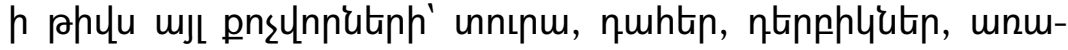

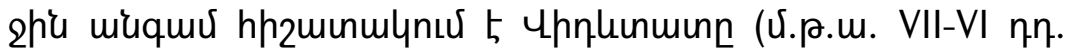

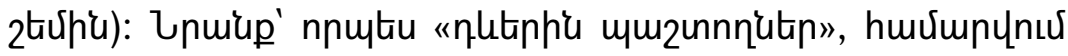

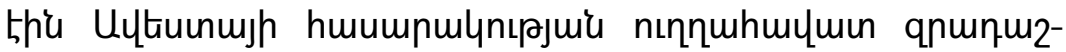

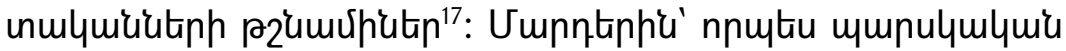
yuslymunniu gtinh, hh2uunulynux 5 <tipnnnunnup ${ }^{18}$ : <nıju

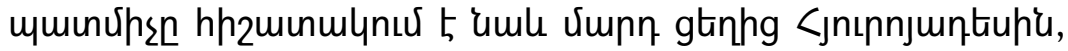

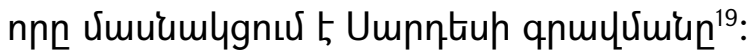

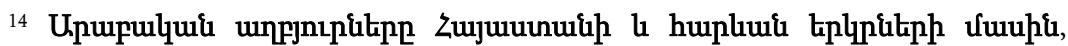

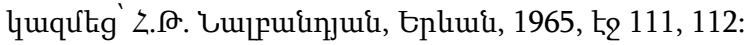

${ }^{15}$ Guidi I., Ostsyrische Bischofe und Bischofssitze im V, VI und VII Jahrhundert, Zeitschrift der Deutschen Morgenlandischen Gesellschaft, Bd. 43, Leipzig, 1889, S. 407.

16 Дьяконов И., История Мидии, Москва-Ленинград, 1956, стр. 92, 381-382; Грантовский Э., Ранняя история иранских племен Передней Азии, Москва, 1970, стр. 374.

17 Дьяконов М., Очерк истории древнего Ирана, Москва, 1961, стр. 62.

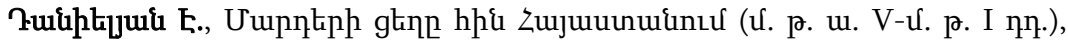
TF Z, 1976, № 1, ㄴo 203:

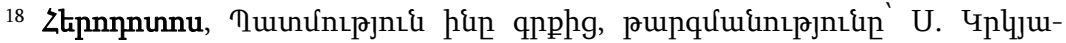

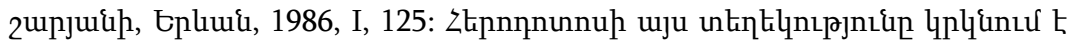
Eluunuphnup (unt' ' ИДПСК, ВДИ, 1948, 1, стр. 246):

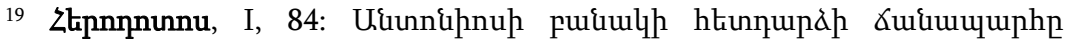

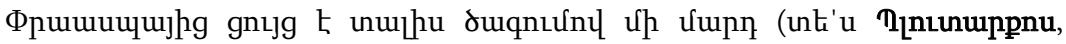

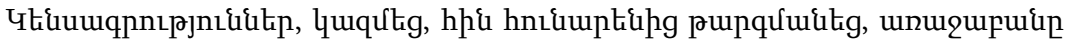

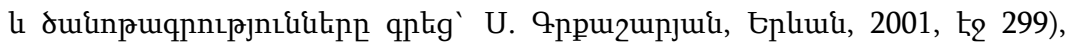




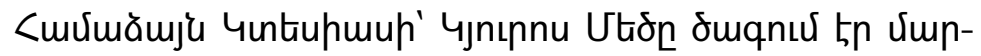

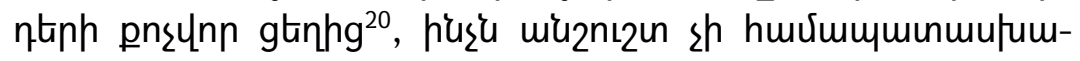

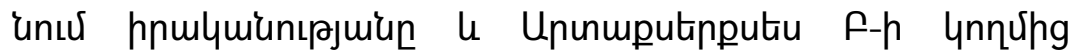

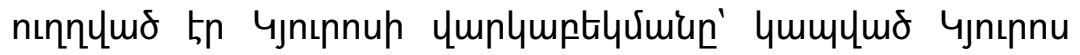

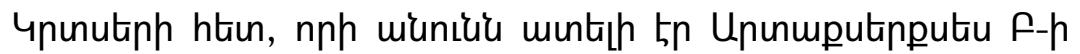

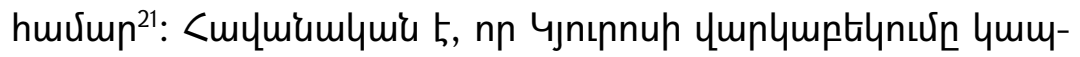

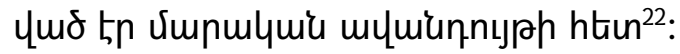

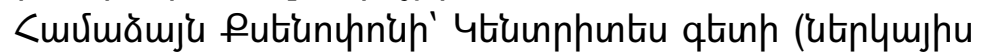

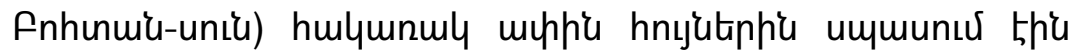

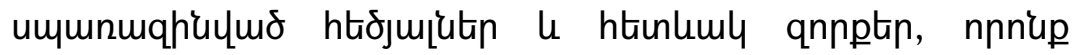

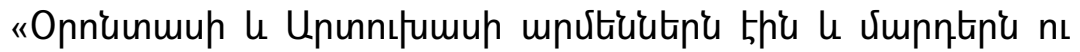

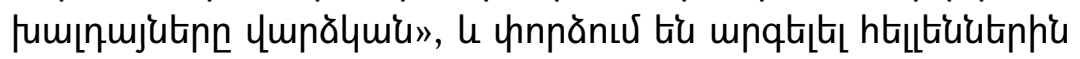

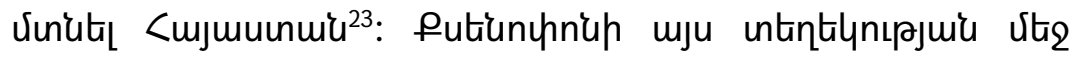

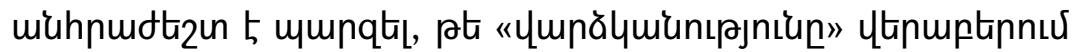

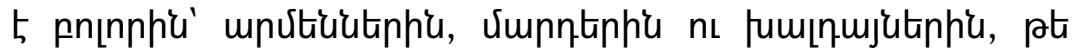

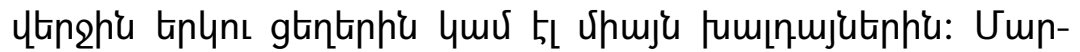

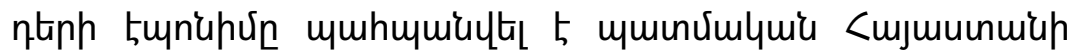

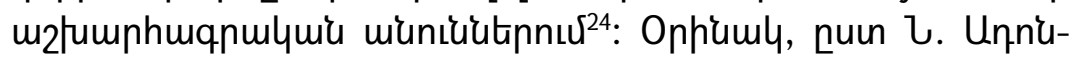

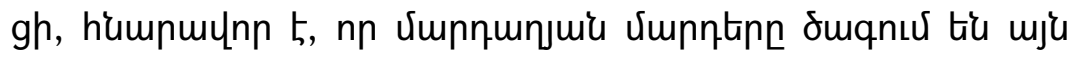

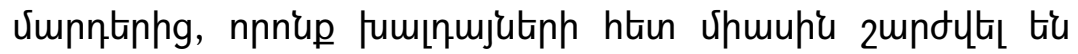

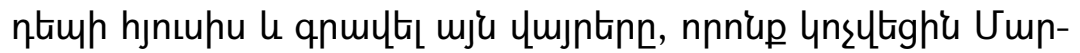

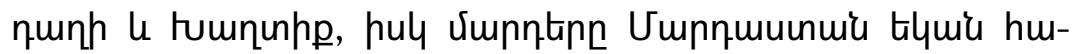

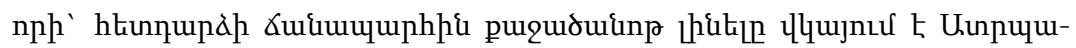

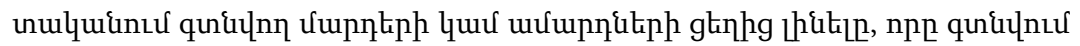
Łр Фpuuuuuujhg uplitip:

${ }^{20}$ Müller C., FHG, Vol. III, pp. 399-400, fr. 66.

${ }^{21}$ Kent R.G., The oldest Old Persian inscriptions, Journal of the American Oriental Society, Vol. 66, 1946, p. 211.

${ }^{22}$ Schubert R., Herodots. Darstellung der Cyrussage, Breslau, 1890, S. 58.

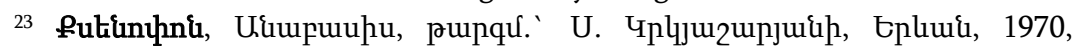
t.2 89:

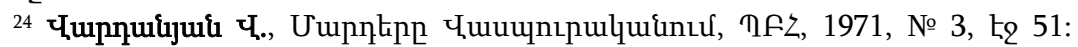

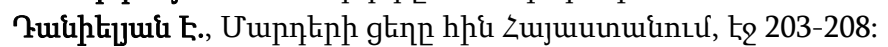




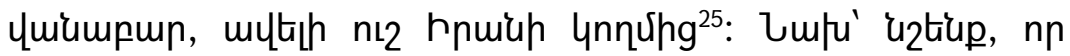

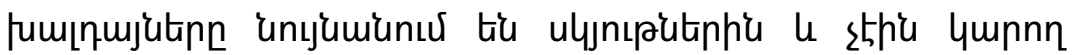

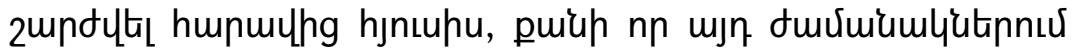

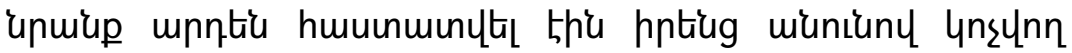

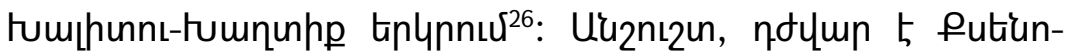

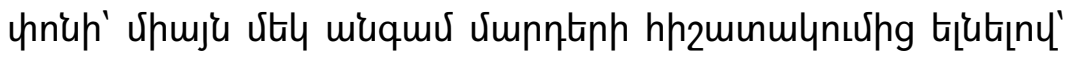

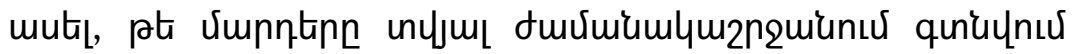

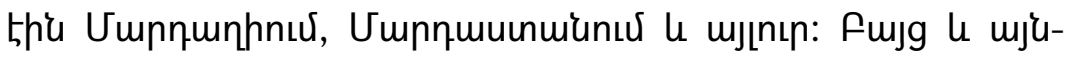

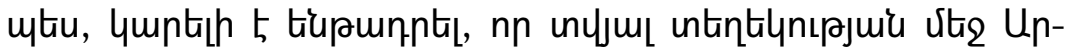

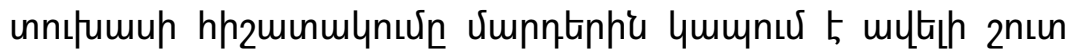

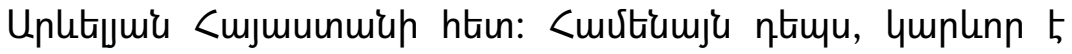

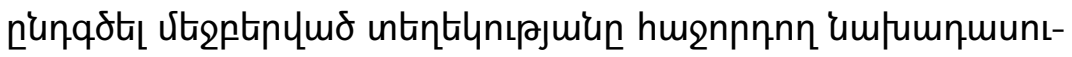

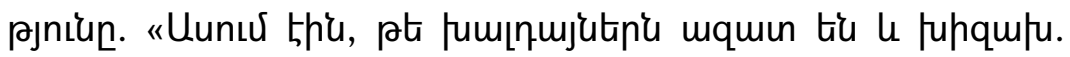

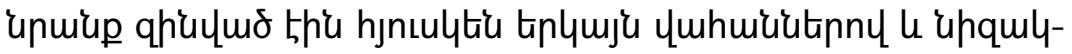

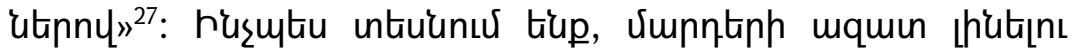

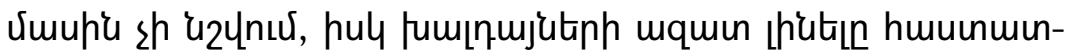

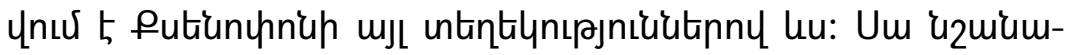

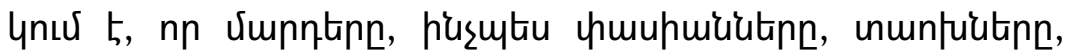

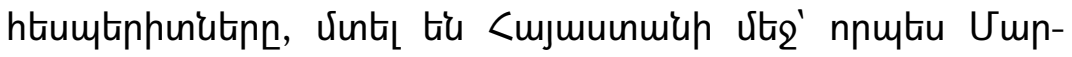

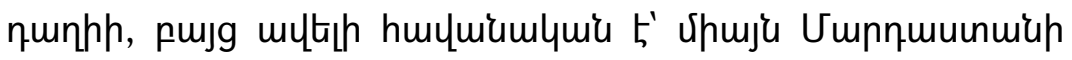

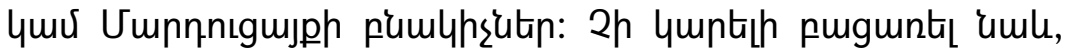

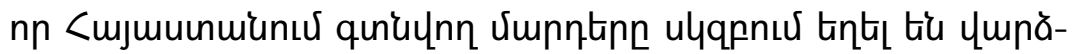

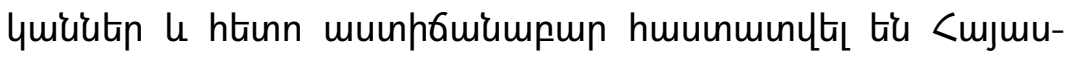
unuiunus:

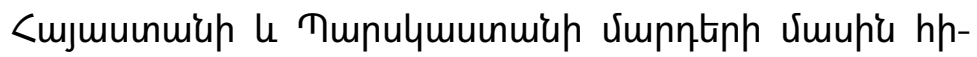

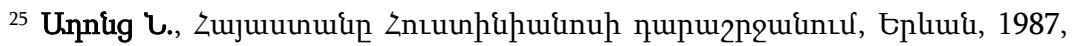
te 464, duinp. 1:

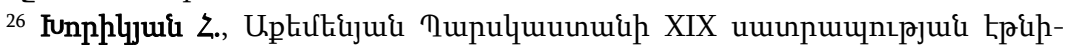

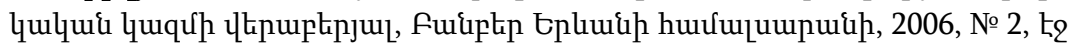
117-120:

${ }^{27}$ Putinuhnq, Uquupuuhu, te 89: 


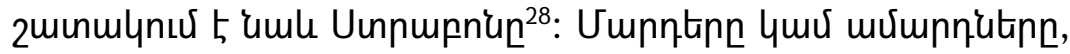

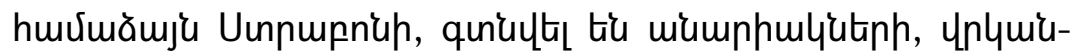

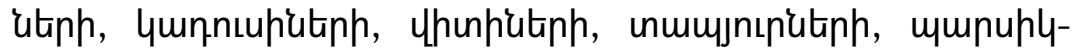

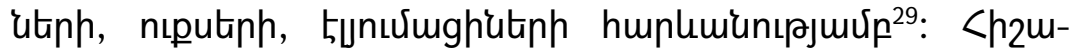

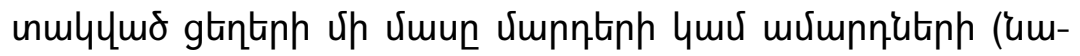

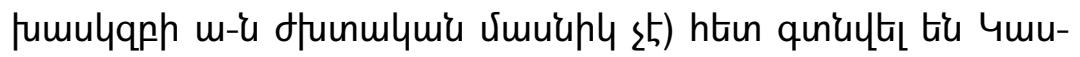

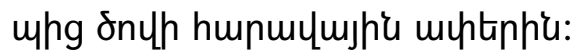

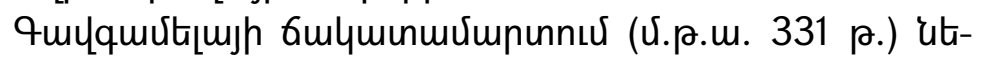

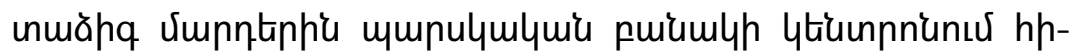

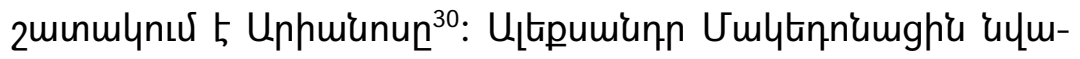

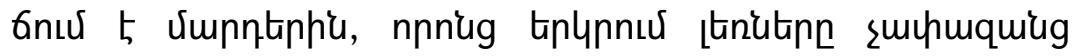

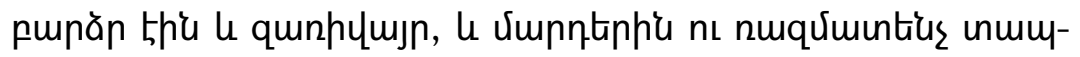

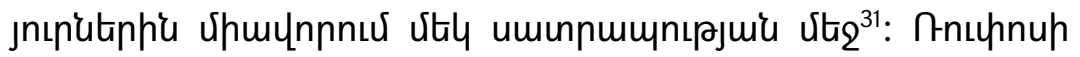

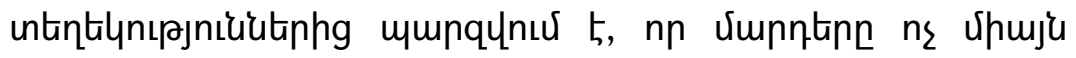

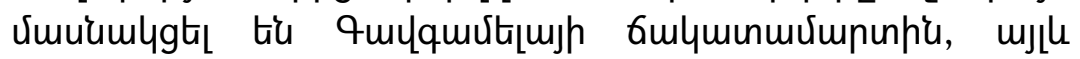

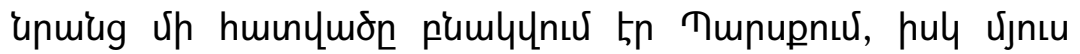

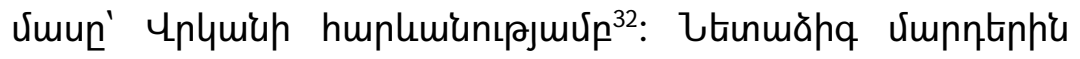

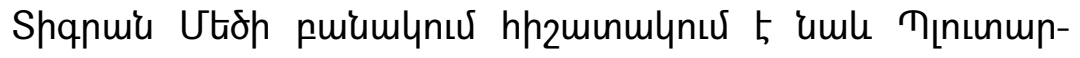

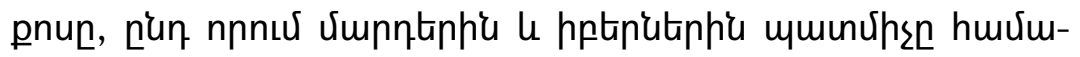

${ }^{28}$ Страбон, стр. 494, 676.

${ }^{29}$ U.u., tr 480, 481, 485, 494:

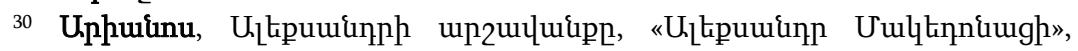
Epluuid, 1987, to 101:

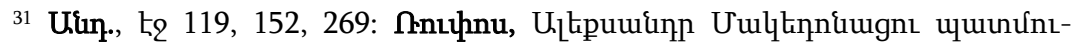

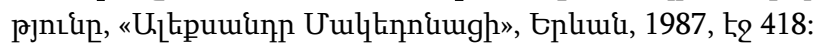

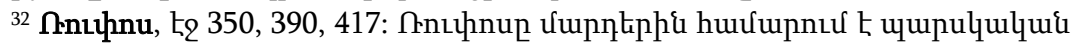

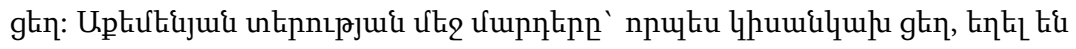
цunḋlumiqtip (unt'u Дандамаев М.A., Луконин В.Г., Культура и экономика

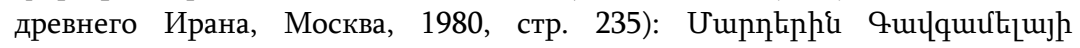

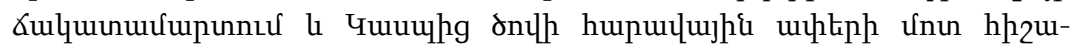

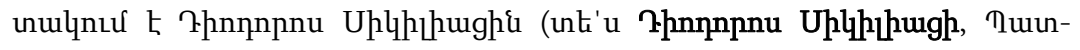

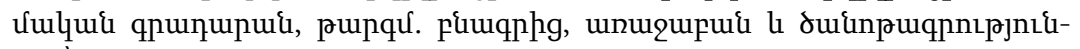

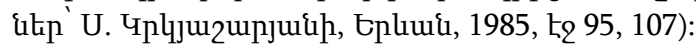




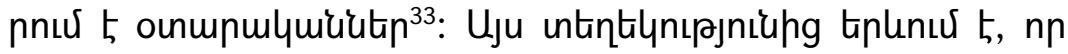

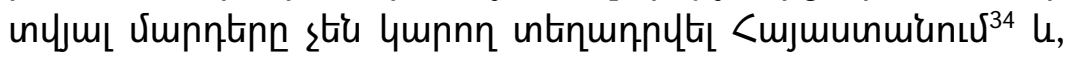

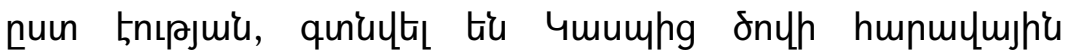

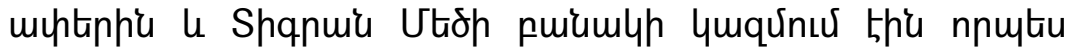

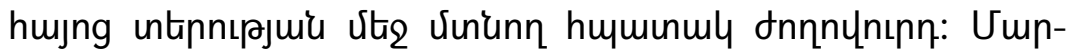

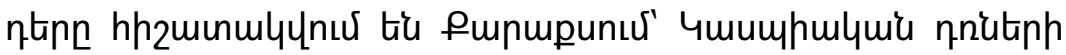
unun ${ }^{35}$ :

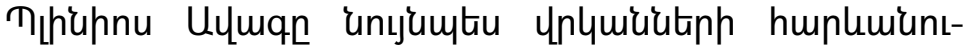

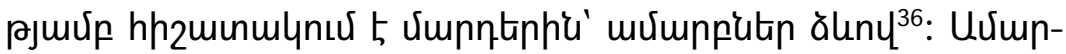

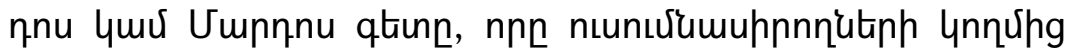

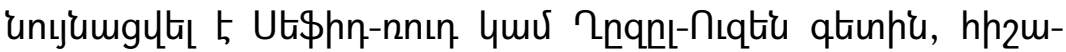

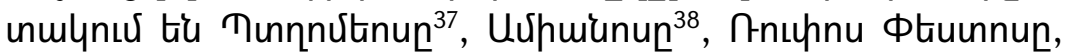

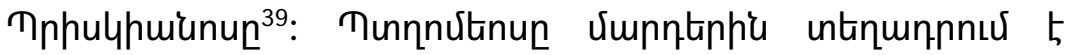

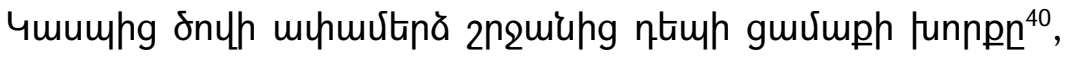

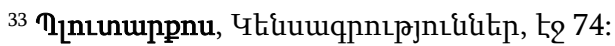

${ }^{34}$ Sulhhunnuh hp2uunuluud funntinp (unt'u Корнелий Тацит, Анналы, т. I,

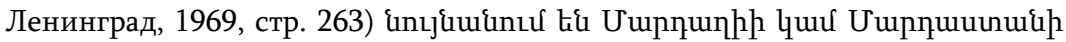
puulhrikiphi:

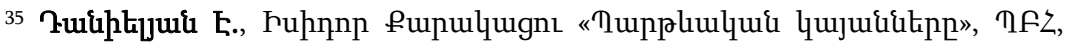
1971, № 4, ㄴ. 174:

${ }^{36}$ Pliny, Natural History, Vol II, VI, 36, p. 364. Uupntipn tifpuplylti tí uupplifiphis (uin., VI, 134, tr 438):

${ }^{37}$ Humbach H., Ziegler S., Ptolemy Geography, book 6, pp. 36-37.

${ }^{38}$ Ammianus Marcellinus, with an English translation by J.C. Rolfe, Vol. II, Cambridge-Massachusetts-London, 1972, Loeb Classical Library, XXIII, 6, 40, p. 372.

${ }^{39}$ Muller C., Geographi Graeci Minores, Vol. II, Parisiis, 1861, pp. 185, 196.

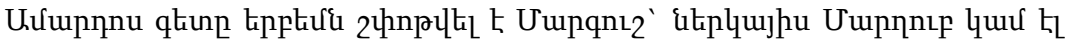
Opunu qtintiph htiu (unt' ' с Страбон, стр. 487):

${ }^{40}$ Humbach H., Ziegler S., Ptolemy Geography, book 6, pp. 42-43. Zưun. Piller K.C., The Cadusii in Archaeology? Remarks on the Achaemenid Period (Iron Age IV) in Gilan and Talesh, Iran and Caucasus, Leiden, Vol. 17, 2013, p. 117. 


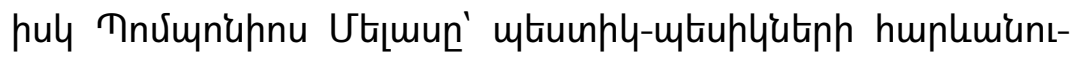

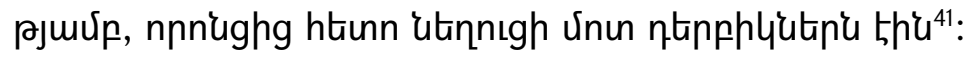

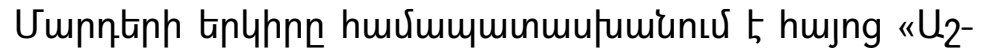

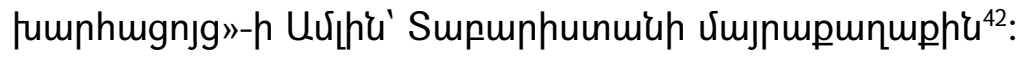

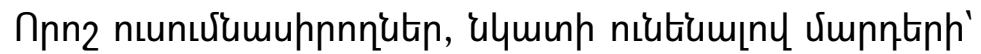

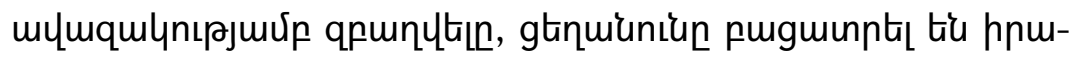

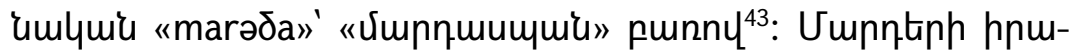

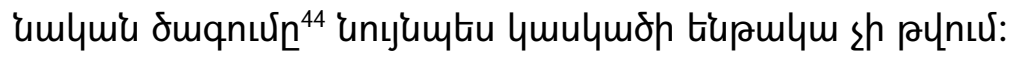

Uimphulititn: Uiumpulyitinn, nuen nuntưumuhnnn-

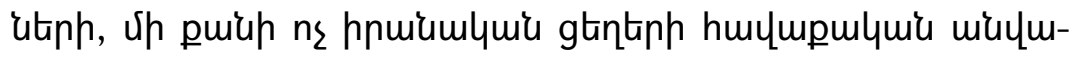

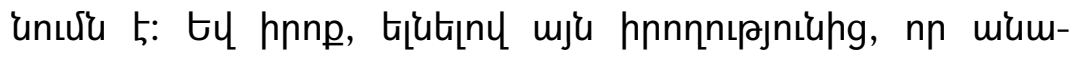

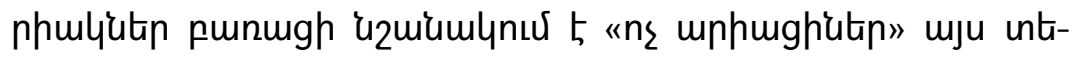

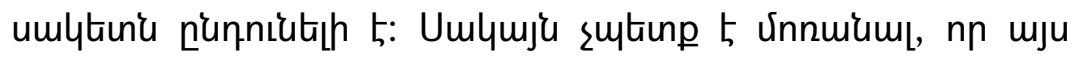

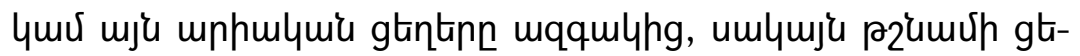

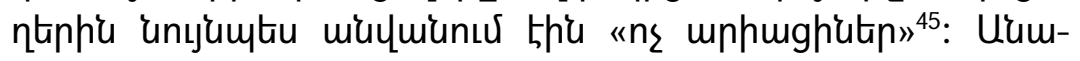

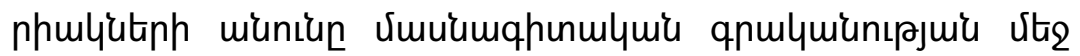

${ }^{41}$ ИДПСК, ВДИ, 1949, 1, стр. 284-285: Thuunhl-ułtuplqutpp Unpupnqh

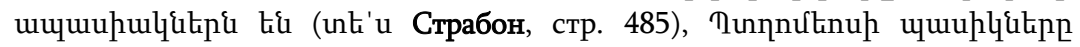
(unt'u Humbach H., Ziegler S., Ptolemy Geography, book 6, pp. 168-169):

${ }^{42}$ Sti' u Uuuntiuuqhpp Zuung, f huunn, E nup, Uiphlhuu-Lhpuiuud, 2003, tq 2157, 2174, 2190: St'u Marquart J., Ėrānšahr nach der Geographie des Ps. Moses Xorenac'i, Berlin, 1901, S. 135; Хуршудян Э., «Города Ирана», Ираннамэ, 2010, № 3, стр. 151.

${ }^{43}$ Geiger W., Ostīrānische Kultur im Altertum, Erlangen, 1882, S. 66. Uupntinn

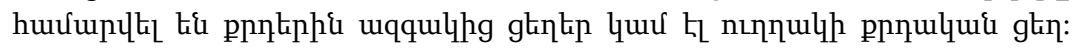

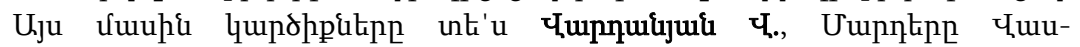
unıpuluuinuर, t, 50:

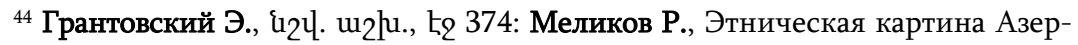
байджана в период ахеменидского владычества (VI-IV вв. до н.э.), Баку,

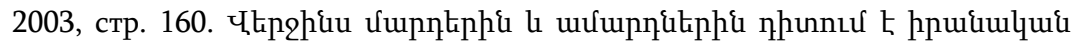

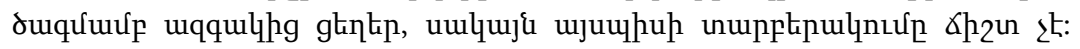

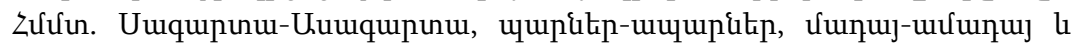
uj] $\{$ :

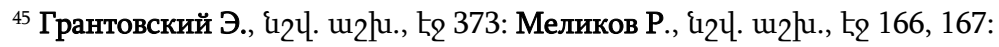




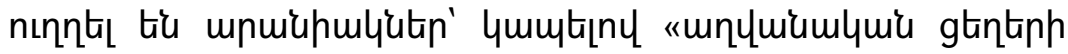

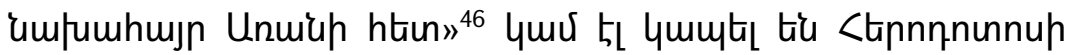

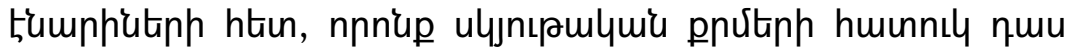

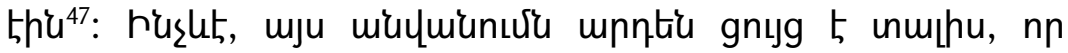

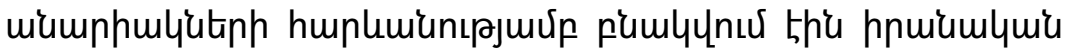

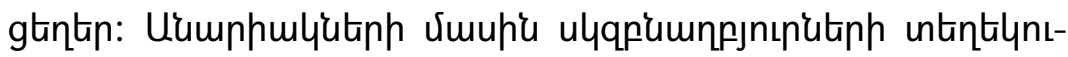

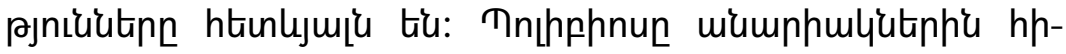

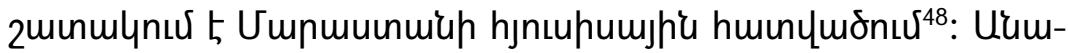

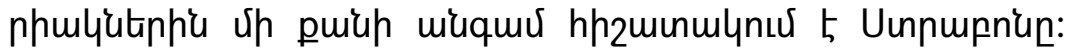

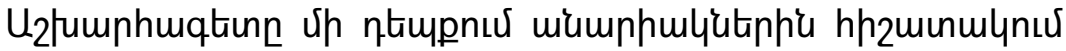

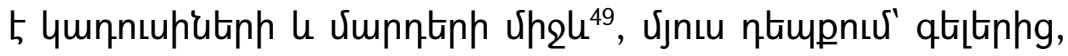
qunnsuhutinhg, uxumpnutinhg, nıhunhutinhg htunn ${ }^{50}$ : Thühnu

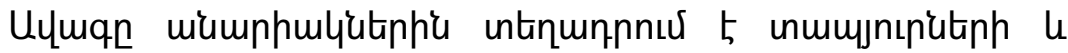

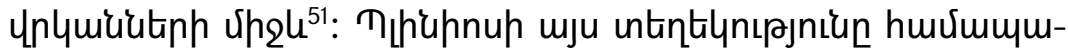

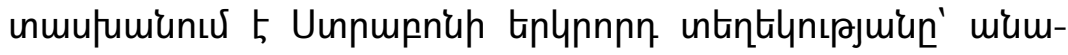

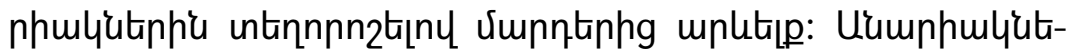

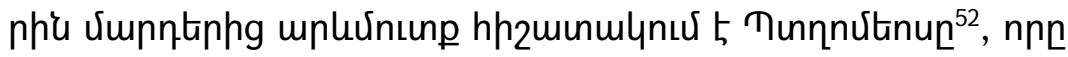

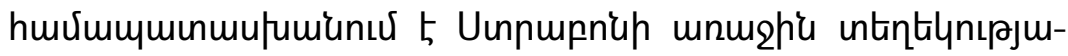

46 Тревер К., Очерки по истории и культуре Кавказской Албании (IV в. до н.э.-VII в. н.э). Москва-Ленинград, 1959, стр. 143.

47 Еремян С.Т., Страна «Махелония» надписи Кааба-и-Зардушт, ВДИ, 1967,

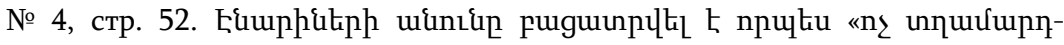
qujh\{» (unt'u Доватур А., Каллистов Д., Шишова И. Народы нашей страны в

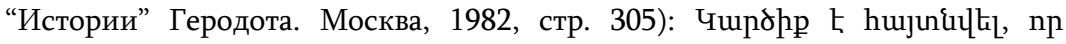

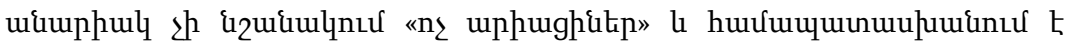

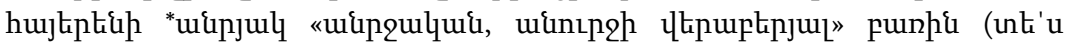

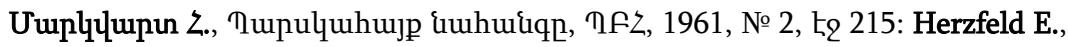
\{2u. u2h., to 196):

${ }^{48}$ ИДПСК, ВДИ, 1947, 3, стр. 301.

${ }^{49}$ Страбон, стр. 480, 485.

50 Uun, to 481:

${ }^{51}$ Pliny, Natural History, Vol. II, VI, 46, p. 370.

${ }^{52}$ Claudii Ptolemaei Geographia, t. II, VI, 2, 5, p. 86. 
un: Utap ympohpny mumphulyutiph tiplns unmpptip untinnnn-

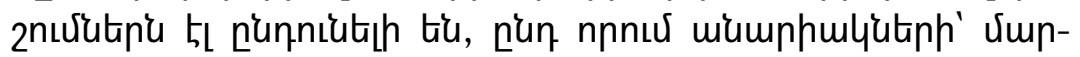

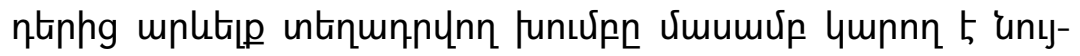

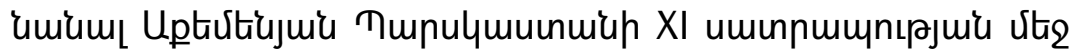

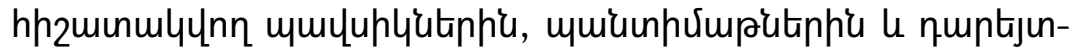

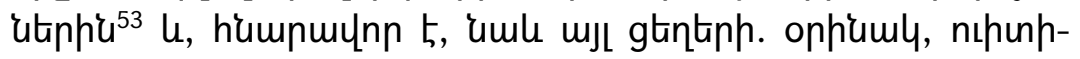

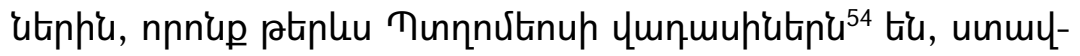

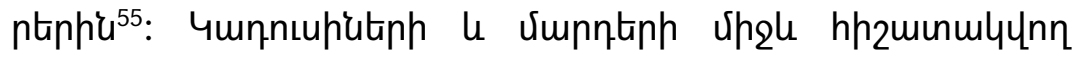

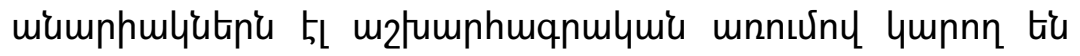

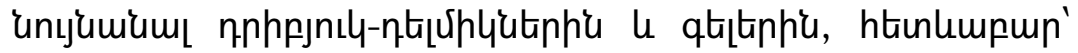

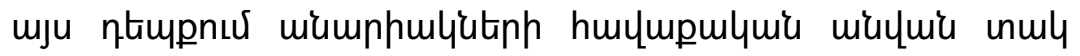

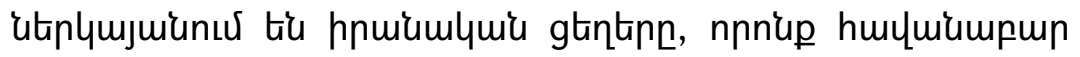

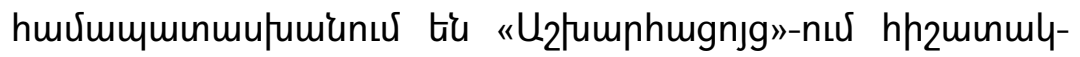
ymo Uump(h)ulymi Umpph ${ }^{56}$ :

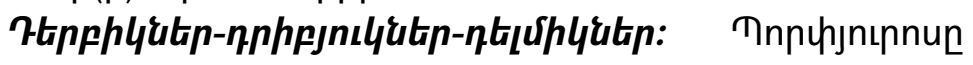

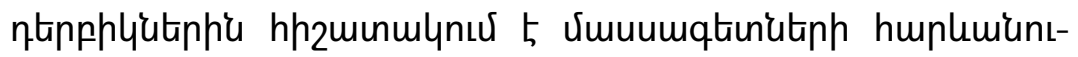

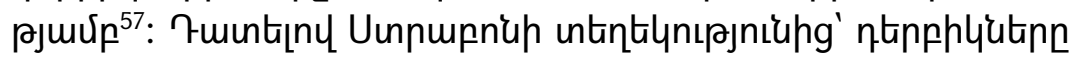

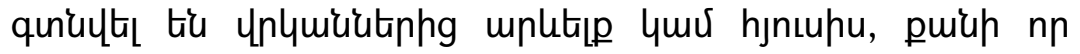

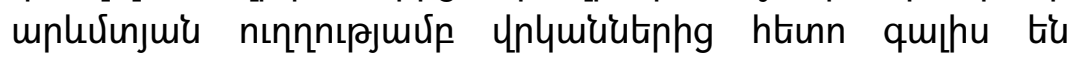

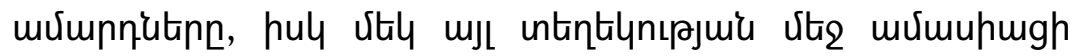

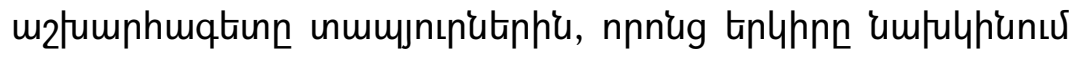

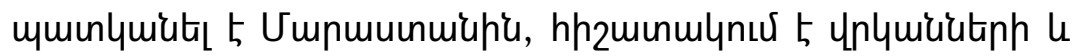

\footnotetext{
53 Zlepnnnunnu, III, 92:

${ }^{54}$ Humbach H., Ziegler S., Ptolemy Geography, book 6, pp. 44-45.

${ }_{55}$ Pliny, Natural History, Vol. II, VI, 46, p. 370.

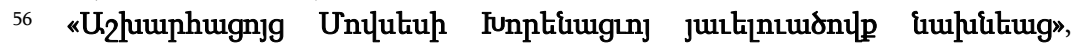
to 12:
}

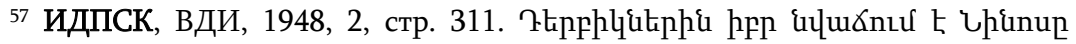

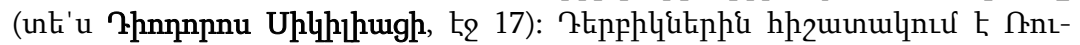
hnup (unt' u Rnıนnu, to 282): 


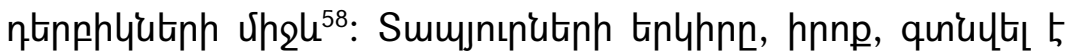

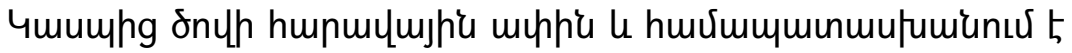

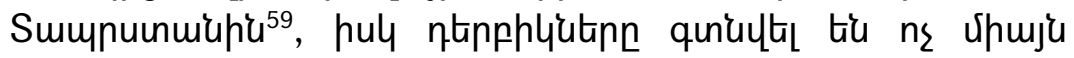

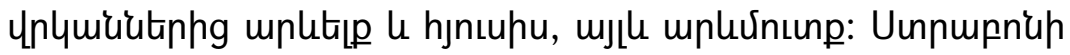

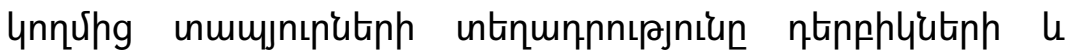

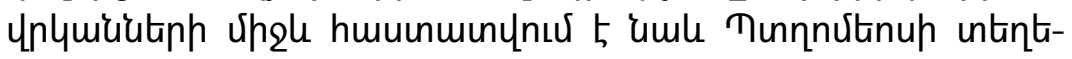

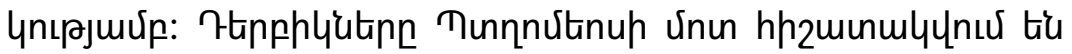

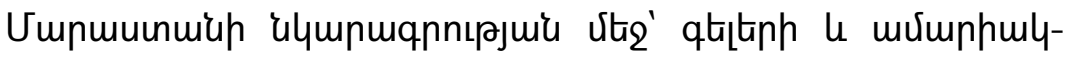

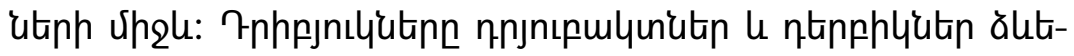

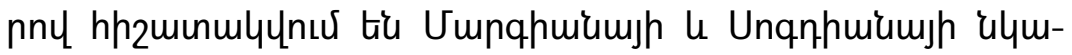

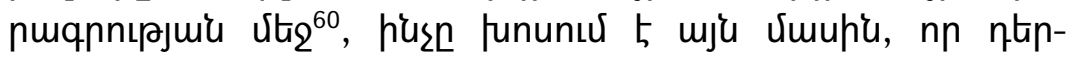

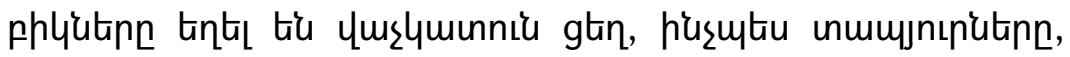

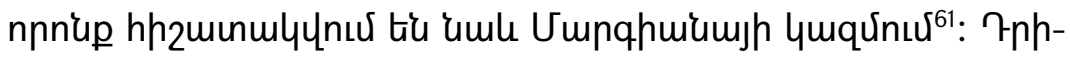

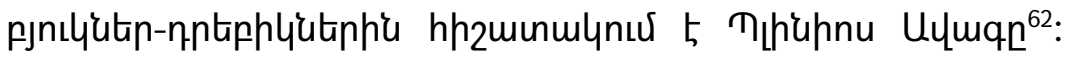

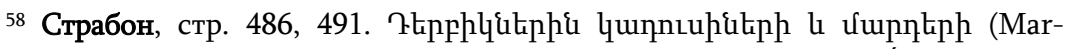

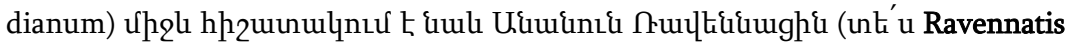
Anonymi Cosmographia, II, 8, p. 60):

59 Sti'u Uuuntiuuqhpp Zujng, f huunnp, te 2157, 2174, 2190; "Zuuuupnưfi

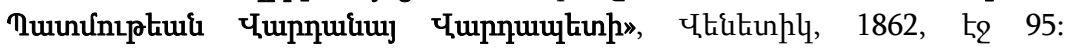

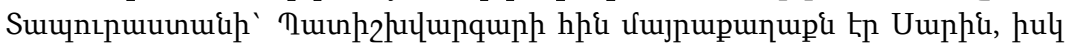

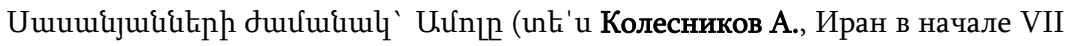
века, Палестинский сборник, Ленинград, 1970, стр. 101), прр «U.2huwp-

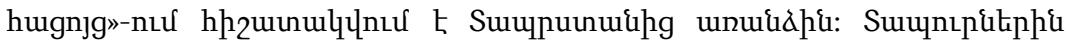

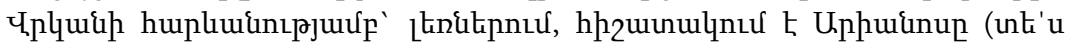

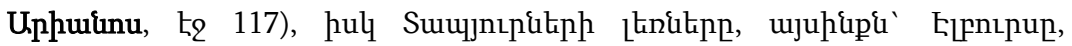
પpluwing onlhg n History of Polybius, Vol. II, by Mr.J. Hampton, London, 1809, p. 218): مnuuh

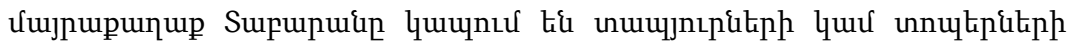
Łр\{uuiuluid htiu (ut' ' Х Хуршудян Э., «Города Ирана», стр. 133):

${ }^{60}$ Humbach H., Ziegler S., Ptolemy Geography, book 6, pp. 42-43, 148-149, 168169; Tarn W.W., Patrocles and the Oxo-Caspian Trade Route, Journal of Hellenic Studies, Vol. 21, 1901, p. 17.

${ }^{61}$ Humbach H., Ziegler S., Ptolemy Geography, book 6, pp. 148-149.

${ }^{62}$ Pliny, Natural History, Vol. II, VI, 48, p. 372. 


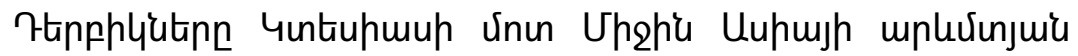

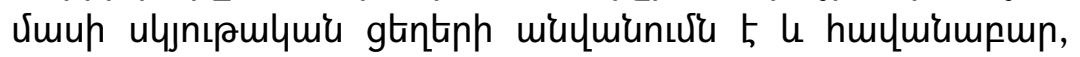

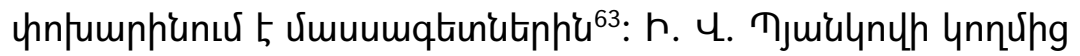

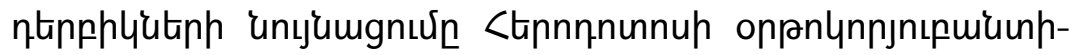

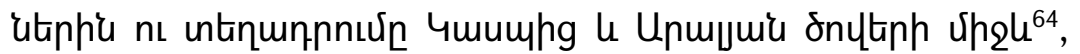

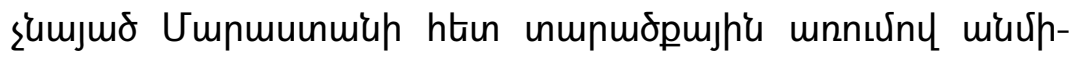

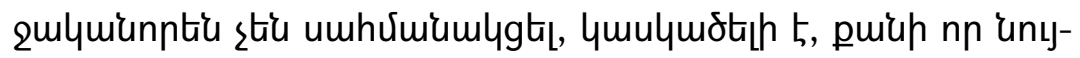

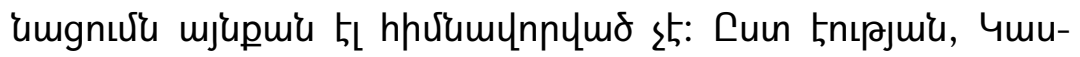

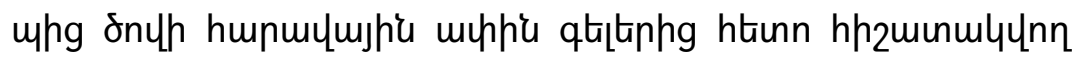

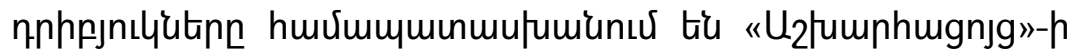

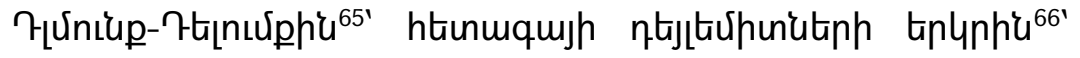

63 Пьянков И.В., Средняя Азия в известиях античного историка Ктесия (текст, перевод, примечания). Душанбе, 1975, стр. 6; Iunphljưq Z., Upt-

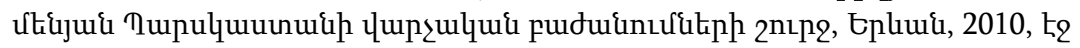
32:

64 Пьянков И.В. «История Персии» Ктесия и среднеазиатские сатрапии Ахеменидов в конце V в. до н. э., ВДИ, 1965, № 2, стр. 43.

${ }^{65}$ Uuuntiuqqpp Zujng, f huunnp, tq 2157, 2174, 2190; «Uppnj hopis utipn]

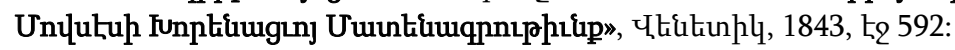

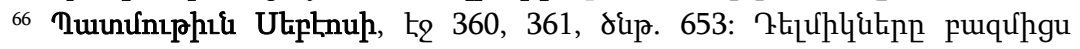

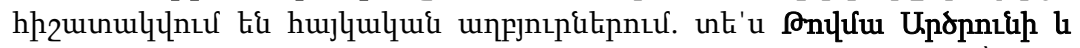

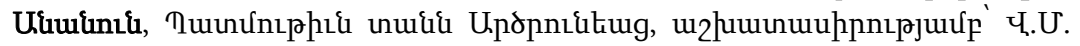

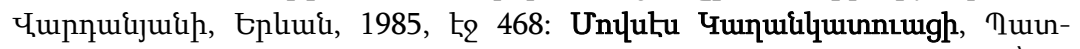

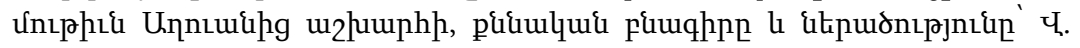

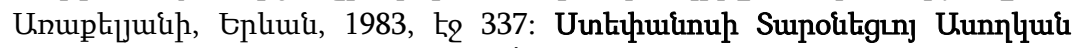

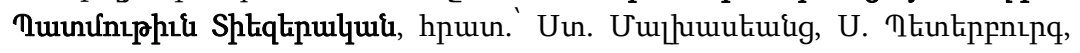

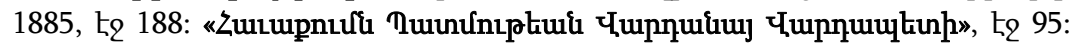

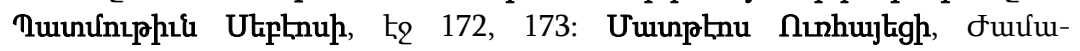

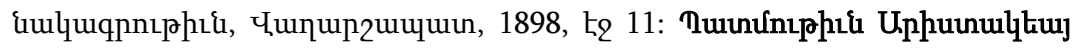

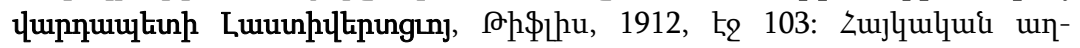

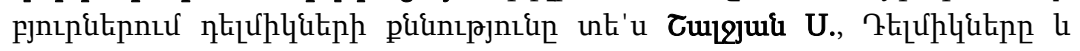

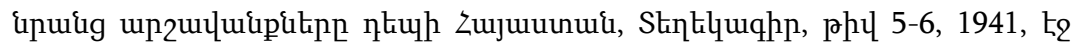

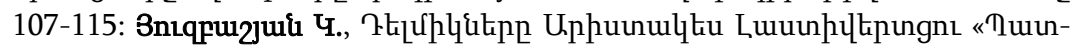
Unıpjui»» Utiq, fuiptip Uunitaunupuia, 1960, phl 5, to 307-311: 


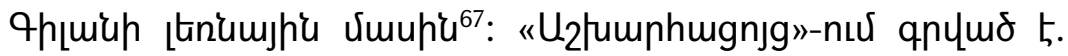

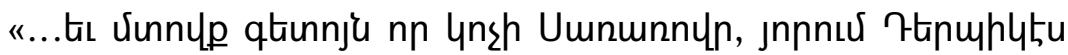

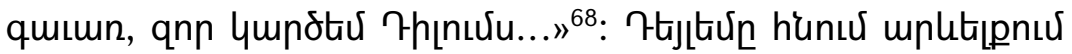

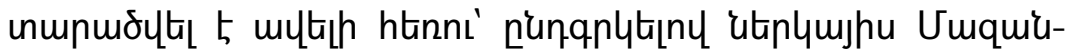
пunmiuh up umun ${ }^{69}$ :

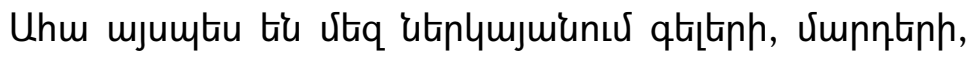

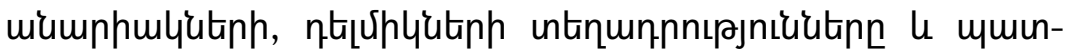

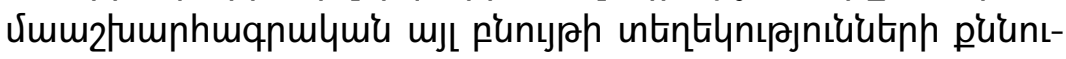
คjniun:

\section{KHORIKYAN HOVHANNES}

\section{ON THE ETHNIC STRUCTURE OF MEDIA}

Keywords: Media, Armenia, Persia, Gelae, Mardi, Anariacae, Derbices, Plutarch, Pliny the Elder, Xenophon, Strabo.

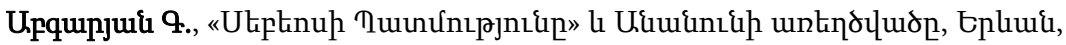
1965, th 199, 200:

67 Колесников А., Иран в начале VII века, стр. 101. О. ঢjnцntptí qu-

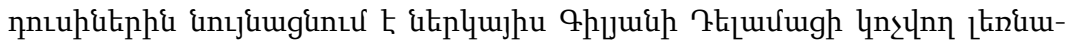

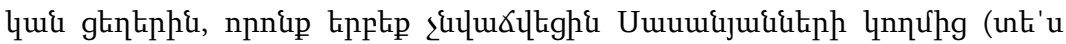
Nöldeke Th., Aufsätze zur Persischen Geschichte, Leipzig, 1887, S. 95): St'u quul Bosworth C.E., Dailamīs in Central Iran: The Kākūyids of Jibāl, Iran, Journal of the British Institute of Persian Studies, Vol. 8, Issue 1, 1970, p. 73.

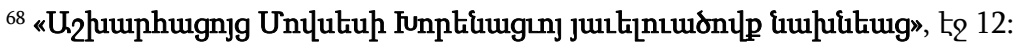

${ }^{69}$ Колесников А. Иран в начале VII века, стр. 101. Ч. Uhinpulhi tiq-

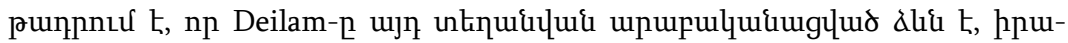

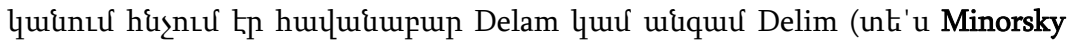
V., La domination de Dailamites, London, Iranica, Twenty Articles, 1964, pp. 12-

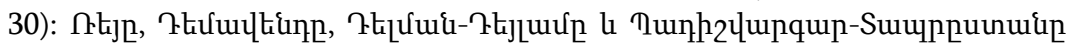

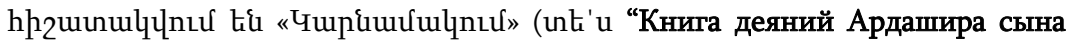
Папака", транскрипция текста, пер. со среднеперс., введ., коммент. и глоссарий О.М. Чунаковой, Москва, 1987, стр. 72, 92). 
The study of the history of Media is very significant for Armenia too, as the past of both countries is closely related to each other in different historical periods. In the following article the information about the Gelae, the Mardi, the Anariacae, the Derbices, kept in the primary source, is being discussed. Research shows that the given tribes belonged to the Iranian World without any exceptions.

Some important and wrinkled issues on the historical geography of the $10^{\text {th }}$ Satrapy were examined in the article, the elucidation of which has an important meaning for studying the history of the Achaemenid Empire and Ancient Iran. 